\title{
Experiments and CFD Simulation of Ferrous Biooxidation in a Bubble Column Bioreactor
}

\author{
S.M. Mousavi ${ }^{1,2}$, A. Jafari ${ }^{3}$, S. Yaghmaei ${ }^{1}$, M. Vossoughi ${ }^{2}$, I. Turunen ${ }^{2}$ \\ ${ }^{1}$ Department of Chemical and Petroleum Engineering, Sharif University of Technology, Tehran, Iran \\ ${ }^{2}$ Department of Chemical Technology, Lappeenranta University of Technology, Lappeenranta, Finland \\ ${ }^{3}$ Laboratory of Engineering Thermodynamics, Department of Energy and Environmental Technology, \\ Lappeenranta University of Technology, Lappeenranta, Finland
}

\begin{abstract}
In the present attempt a set of experiments and a 3D simulation using a commercially available computational fluid dynamics package (FLUENT) were adopted to investigate complex behavior involving hydrodynamics and ferrous biological oxidation in a gas-liquid bubble column reactor. By combining the hydrodynamics and chemical species transport equations, the velocity field, air volume fraction and ferrous biooxidation rate in the column were simulated. The kinetic model proposed by Nemati and Webb (1998) was used to simulate the biooxidation rate in the column. Gas-liquid interactions were modeled using an Eulerian model in three dimensions. The effects of inlet air velocity and initial substrate $\left(\mathrm{Fe}^{+2}\right)$ concentration on the velocity field, air volume fraction and biooxidation rate of ferrous iron in the column were investigated. To validate the model, simulation was compared with the experimental data in the presence of Acidithiobacillus ferrooxidans in an aerated column where the superficial gas velocity was adjusted between 0 and $0.5 \mathrm{~m} / \mathrm{s}$. It was found that the initial ferrous concentration and the inlet air velocity had a pronounced effect on the ferrous biooxidation rate. The results indicated that the maximum biooxidation rate can be obtained at superficial air velocity of 0.1 $\mathrm{m} / \mathrm{s}$ and initial ferrous concentration of $6.7 \mathrm{~g} / \mathrm{L}$.
\end{abstract}

Keywords - CFD simulation, velocity field, air volume fraction, ferrous biooxidation rate, bubble column reactor.

\section{INTRODUCTION}

Bubble column reactors are attracting increasing academic and industrial research interest in view of their many potential applications. Bubble columns are widely used as gas-liquid contactors and as reactors in the chemical, petrochemical and biochemical industries. Effective mixing as well as high interfacial area between the phases, leading to improved heat and mass transfer characteristics, relatively cheap to install and the lack of moving parts, are the factors that render under bubble columns an attractive choice as reactors for the described processes.

In chemical and biochemical process engineering, much works have been devoted to either kinetic modeling or fluid dynamics. Most works have been performed under the assumption of idealized conditions. Either the reactor was assumed to be an ideal model case or the fluid dynamics was considered in a realistic way, but mass transfer and chemical reaction were omitted. Despite the widespread application of bubble columns and substantial research efforts devoted to understand their behavior, detailed knowledge on the fluid flow, mass transfer and chemical reactions as well as their interactions are still lacking. However, the scale-up of bubble column is still poorly understood because of the complexity of the flow patterns and their unknown behavior under different sets of design parameters.

Understanding the complexity of the fluid dynamics in bubble column and airlift reactors is important due to their application in the chemical and bioprocess industries. Knowledge of the hydrodynamics of such reactors helps to determine the efficiency of biochemical production rates through transport processes such as inter-phase oxygen transfer, mixing of nutrients and reactants plus the effects that $\mathrm{pH}$ has on micro-organisms growth, metabolic pathways and cell lyses. Also of importance is knowledge of the influence of the biomass on the gas phase through inter-phase interactions and the impact the biomass has on the liquid phase viscosity [1].

Study of the flow hydrodynamics in bubble columns involves the use of experimental techniques and computational fluid dynamics (CFD). The potential of CFD for describing the hydrodynamics of bubble columns has been established by Several publications, for example [2]-[6]. An important advantage of the CFD approach is that column geometry and scale effects are automatically accounted. The success of the CFD simulation strategy is however crucially dependent on the proper modeling of the momentum exchange, or drag coefficient between the gas and liquid phases. CFD modeling of gas-liquid two-phase flows has shown remarkable progress over the last decade. The methods developed include the volume of fluid methods, dispersed phase models, Eulerian two-fluid models, and the algebraic slip mixture models. The two most common approaches to modeling bubble columns are the Euler-Euler or two-fluid approach and the Euler-Lagrange or discrete bubble approach. In the Euler-Euler approach, both phases (the continuous liquid phase and the dispersed gas 
phase) are modeled as two interpenetrating continua. In the Euler-Lagrange approach on the other hand, the volume averaged Navier-Stokes equations are used to describe the motion of the liquid phase and each bubble is tracked on basis of a balance of forces acting upon.

In view of the fact that the microbial oxidation of ferrous iron to the ferric form is an essential sub-process in many biological processes, the developing of an understanding to obtain optimum conditions for this sub-process is critical. Bacterial leaching is an established biotechnology that uses the ability of Acidithiobacillus ferrooxidans to oxidize ferrous iron. This microorganism has the capability to carry out processes of biosorption and bioprecipitation of heavy metal ions, which have important environmental applications [7]. Another application of the acidophilic ferrous iron-oxidizing bacteria can be found in a process proposed for removal of hydrogen sulfide from gases [8]. In this process the removal of hydrogen sulfide is achieved via two steps: the chemical oxidation of the sulfide by $\mathrm{Fe}^{3+}$ and the bacterial regeneration of $\mathrm{Fe}^{3+}$ as leaching agent [9]-[10].

The objective of this research was to develop a fundamental understanding of the hydrodynamics and interactions with the chemistries involved in the bubble column reactor to maximize overall efficiency for the ferrous biological oxidation according to the following reaction:

$2 \mathrm{Fe}^{2+}+2 \mathrm{H}^{+}+1 / 2 \mathrm{O}_{2} \stackrel{\text { A. ferrooxidans }}{\longrightarrow} 2 \mathrm{Fe}^{3+}+\mathrm{H}_{2} \mathrm{O}$

In this work $\mathrm{CFD}$ was used in the Eulerian framework to describe the hydrodynamics of the bubble column bioreactor. A kinetic model was applied to investigate the influence of some variables on biooxidation rate of ferrous ion in an aerated column reactor.

\section{EXPERIMENTAL PROCEDURES}

\section{Materials and Methods}

\section{A. Microorganism and Medium}

A. ferrooxidans was used as an inoculum in the experimental part. The medium for growth and maintenance of cells was contained (in g/L): $\mathrm{FeSO}_{4} .7 \mathrm{H}_{2} \mathrm{O}: 33.4,\left(\mathrm{NH}_{4}\right)_{2} \mathrm{SO}_{4}: \quad 0.4$, $\mathrm{MgSO}_{4} \cdot 7 \mathrm{H}_{2} \mathrm{O}: 0.4$, and $\mathrm{K}_{2} \mathrm{HPO}_{4}: 0.4$ [11]. To prepare the medium the iron solution was filtered using Whatman paper 0.2 $\mu \mathrm{m}$, and the basal salt solution was autoclaved at $121^{\circ} \mathrm{C}$ and 15 psig for $20 \mathrm{~min}$ and after cooling solutions were combined. More details about microorganism and medium can be found in the previous work [12].

\section{B. Biooxidation Procedure}

Biooxidation experiments were carried out in a bubble column reactor consisting of three parts: top, main column with water jacket and bottom section with an air diffuser (Fig. 1). The diameter and height of column were 7.5 and $70 \mathrm{~cm}$, respectively. Total working volume of bioreactor was about $3 \mathrm{~L}$. Compressed air was sparged at five different levels from the bottom into the column. The top part of the reactor had a $15 \mathrm{~cm}$ diameter and $10 \mathrm{~cm}$ height and was employed to prevent the overflow of liquid from the reactor. In order to provide a constant temperature, bioreactor was maintained at $32^{\circ} \mathrm{C}$ using a water jacket. The bioreactor contained 2.7 liters of medium and $10 \%(\mathrm{v} / \mathrm{v})$ inoculum. The initial cells concentration was about $4 \times 10^{8}$ cells $/ \mathrm{mL}$. During the experiments, $\mathrm{pH}$ was adjusted to 1.5 by addition of $1 \mathrm{~N} \mathrm{H}_{2} \mathrm{SO}_{4}$. To obtain variations of ferrous biooxidation rate against initial ferrous concentration and inlet air velocity a set of experiments were carried out at different conditions. Ferrous, ferric and bacterial concentrations were measured regularly. Water was added to the reactor to compensate for evaporation losses. Dissolved oxygen was measured by a digital D.O. meter (Electronics, India). The analysis procedures for the bacterial concentration, determination of iron ions and $\mathrm{pH}$ are similar to described in [12].

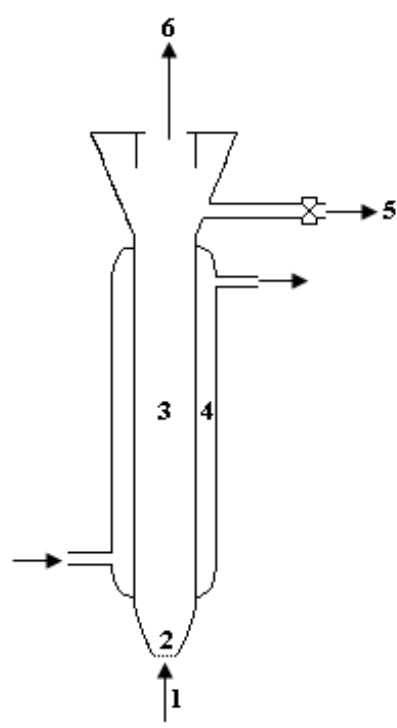

Fig.1: Schematic diagram of the bubble column bioreactor used in the experiments (1: input air; 2: air sparger; 3: main column; 4: water jacket; 5 : sampling port; 6 : output air).

\section{MATHEMATICAL MODELING AND NUMERICAL METHOD}

\section{A. Kinetic Model}

The kinetic model proposed by Nemati and Webb [13] (Eq. 2 ) was used in the simulation. The experimental data obtained from the bioreactor were compared with the kinetic model to ensure the suitability of the model for our simulations. The model includes the effects of temperature, ferrous iron, and bacterial concentrations, also incorporates terms for substrate $\left(\mathrm{Fe}^{2+}\right)$ and cell inhibition. Values for the constants in the kinetic model are summarized in Table 1. 


$$
\frac{d\left[\mathrm{Fe}^{2+}\right]}{d t}=K \frac{[X]\left[\mathrm{Fe}^{2+}\right]}{K_{m}^{\prime}\left(1+\frac{[X]}{K_{i}^{\prime}}\right)+\left[F e^{2+}\right]+\left(1-\frac{[X]}{\beta}\right) \frac{\left[F e^{2+}\right]^{2}}{\alpha}}
$$

where $\left[\mathrm{Fe}^{2+}\right]=$ ferrous iron concentration $\left(\mathrm{kg} / \mathrm{m}^{3}\right) ;[X]=$ bacterial concentration (cells/ $\mathrm{mL}) ; K_{m}^{\prime}=$ apparent saturation constant $\left(\mathrm{kg} / \mathrm{m}^{3}\right) ; K_{i}^{\prime}=$ cell inhibition coefficient (cells/ mL); $\alpha$ and $\beta$ are constants with values of $26.1 \mathrm{~kg} / \mathrm{m}^{3}$ and $7.8 \times 10^{8}$ cells $/ \mathrm{mL}$, respectively and $K$ is the rate constant $\left(\left(\mathrm{kmol} / \mathrm{m}^{3} . \mathrm{h}\right) /(\right.$ cells $\left./ \mathrm{mL})\right)$ which is defined as:

$K=K_{0} e^{-E_{a} / R T}$

where $E_{a}=$ activation energy $(\mathrm{kJ} / \mathrm{mol}) ; \quad R=$ universal gas constant $(\mathrm{kJ} / \mathrm{K} . \mathrm{mol}) ; K_{0}=$ frequency factor $\left(\left(\mathrm{kmol} / \mathrm{m}^{3} . \mathrm{h}\right) /(\right.$ cells $\left./ \mathrm{mL})\right)$ and $T=$ absolute temperature $(\mathrm{K})$.

Table 1: Coefficients of the overall kinetic model for the biological oxidation of ferrous iron [13]

\begin{tabular}{|c|c|}
\hline $\begin{array}{c}\text { Coefficien } \\
t\end{array}$ & Value \\
\hline$K_{0}$ & $\begin{array}{c}114.96\left(\mathrm{kmol} / \mathrm{m}^{3} . \mathrm{h}\right) /(\text { cells } / \mathrm{mL}) \text { or } \\
6438\left(\mathrm{~kg} / \mathrm{m}^{3} . \mathrm{h}\right) /(\text { cells } / \mathrm{mL})\end{array}$ \\
\hline$E_{a}$ & $68.4(\mathrm{~kJ} / \mathrm{mol})$ \\
\hline$K_{m}^{\prime}$ & $\begin{array}{c}1.2 \times 10^{-3}\left(\mathrm{kmol} / \mathrm{m}^{3}\right) \text { or } 0.0672 \\
\left(\mathrm{~kg} / \mathrm{m}^{3}\right)\end{array}$ \\
\hline$K_{i}^{\prime}$ & $2.68 \times 10^{7}($ cells $/ \mathrm{mL})$ \\
\hline$\alpha$ & $0.466\left(\mathrm{kmol} / \mathrm{m}^{3}\right)$ or $26.1\left(\mathrm{~kg} / \mathrm{m}^{3}\right)$ \\
\hline$\beta$ & $7.8 \times 10^{8}($ cells $/ \mathrm{mL})$ \\
\hline
\end{tabular}

\section{B. Eulerian Approach}

The governing equations in this approach can be derived by ensemble averaging the fundamental conservation equations for each phase to describe the motion of liquid and gas in a bubble column. Both the continuous and the dispersed phases are modeled in the Eulerian frame of reference as interpenetrating continua. The mass and momentum balance equations are written separately for each phase. The momentum equations of the phases interact with each other through inter-phase momentum exchange terms. The continuity equation for each phase is written as

$\frac{\partial\left(\alpha_{k} \rho_{k}\right)}{\partial t}+\nabla \cdot\left(\alpha_{k} \rho_{k} \boldsymbol{u}_{k}\right)=0$

where $\alpha_{k}, \rho_{k}$ and $\boldsymbol{u}_{k}$ are the volume fraction, the density, and the phase averaged velocity of the kth phase, respectively.

The equation of conservation of momentum for each phase is:

$\frac{\partial\left(\alpha_{k} \rho_{k} \boldsymbol{u}_{k}\right)}{\partial t}+\nabla .\left(\alpha_{k} \rho_{k} \boldsymbol{u}_{k} \boldsymbol{u}_{k}\right)=-\alpha_{k} \nabla p+\alpha_{k} \rho_{k} \boldsymbol{g}+$

$\nabla .\left(\alpha_{k} \tau_{k}\right)+\nabla .\left(\alpha_{k} \rho_{k} \boldsymbol{u}_{k}^{\prime} \boldsymbol{u}_{k}^{\prime}\right)+\boldsymbol{F}_{k l}$ where $p$ is the pressure, $\boldsymbol{g}$ is the gravity acceleration, and $\boldsymbol{F}_{k l}$ is the interfacial momentum exchange between phase $\mathrm{k}$ and phase 1. $\tau_{k}$ is the viscous stress tensor, which can be expressed by

$\tau_{k}=\mu_{k}\left(\nabla \boldsymbol{u}_{k}+\nabla \boldsymbol{u}_{k}^{T}\right)-\frac{2}{3} \mu_{k} \nabla \cdot u_{k} \boldsymbol{I}$

where $\mu_{k}$ is the viscosity of the kth phase, and $\alpha_{k} \rho_{k} \boldsymbol{u}_{k}^{\prime} \boldsymbol{u}^{\prime}$ is the turbulent stress tensor that must be closed by an appropriate multiphase turbulence model. Because of the loss of information in the averaging process, several correlations (such as the interfacial momentum exchange term $\boldsymbol{F}_{k l}$ in Eq. (5)) appear in the macroscopic equations that must be closed in terms of known variables [14].

The momentum exchange between gas phase (subscript $\mathrm{G}$ ) and liquid phase (subscript L) is given by

$$
\boldsymbol{F}_{L, G}=\frac{3}{4} \rho_{L} \frac{\varepsilon_{G}}{d_{b}} C_{D}\left(\boldsymbol{u}_{G}-\boldsymbol{u}_{L}\right)\left|\boldsymbol{u}_{G}-\boldsymbol{u}_{L}\right|
$$

here, the inter-phase drag coefficient is calculated from [15]:

$C_{D}=\frac{2}{3 \sqrt{E \ddot{O}}}$

Where $E \ddot{o}=\frac{d\left(\rho_{L}-\rho_{G}\right) d_{b}^{2}}{\sigma}$

and $d_{b}$ is the equivalent diameter of the bubbles. Note that the rise velocity of bubbles is practically independent of the bubble size in the 3-8 $\mathrm{mm}$ range. In the simulations reported here, a bubble diameter $3 \mathrm{~mm}$ has been chosen.

In the present analysis only the drag force contribution to $\boldsymbol{F}_{L, G}$ have been included, following the works of Sanyal et al. [2] and Sokolichin and Eigenberger [3] and the added mass and lift force contributions were both ignored.

For the continuous phase (liquid phase) the turbulent contribution to the stress tensor was evaluated by means of $k-\varepsilon$ model described by Sokolichin and Eigenberger [3] using standard single-phase parameters $C_{\mu}=0.09, C_{1 \varepsilon}=1.44, C_{2 \varepsilon}=1.92, \sigma_{k}=1$ and $\sigma_{\varepsilon}=1.3$ and no turbulence model was used for calculating the velocity fields of the dispersed bubble phase.

The conservation equation for transport species takes the following general form:

$\rho\left(\frac{\partial y_{i}}{\partial t}\right)+\rho \nabla \cdot\left(\boldsymbol{u} y_{i}\right)=-\nabla \cdot \boldsymbol{J}_{\boldsymbol{i}}+S_{i}$

where $y_{i}$ is the local mass fraction of ith species, $S_{i}$ is the source term for ith species due to the reaction, and $\boldsymbol{J}_{\boldsymbol{i}}$ is the diffusion flux of species $i$, which arises due to concentration gradients. Diffusion flux can be written as:

$\boldsymbol{J}_{\boldsymbol{i}}=-\rho D_{i, m} \nabla y_{i}$ 
here $D_{i, m}$ is the diffusion coefficient for species $i$ in the mixture. An equation of this form will be solved for $N-1$ species where $N$ is the total number of fluid phase species present in the system.

\section{Numerical Implementation}

In this research a commercial grid-generation tool, GAMBIT 2.2 (of Fluent Inc., USA) was used to create the geometry and generate the grids. It is very important to use adequate number of computational cells while numerically solving the governing equations over the solution domain. To divide the geometry into discrete control volumes, more than $4.5 \times 10^{5}, 3 \mathrm{D}$ tetrahedral computational cells and $9.4 \times 10^{4}$ nodes were used. In addition more than $4.1 \times 10^{4}$ triangular elements were used at the inlet and outlet. Figure 2 shows the schematic and dimensions of the computational domain and the reactor grid. (a)

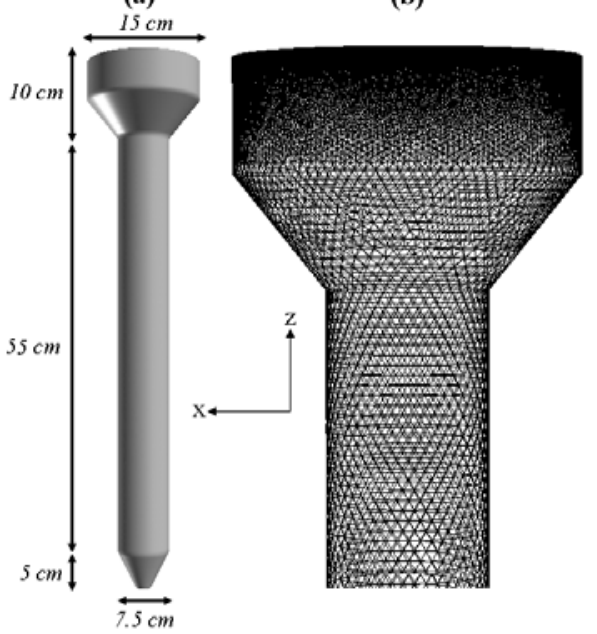

(c)

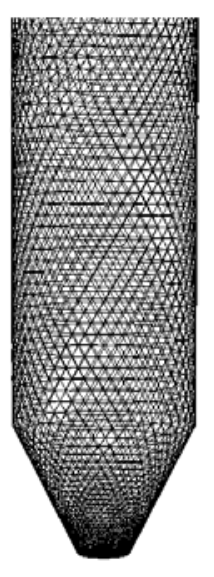

Fig. 2: (a) Schematic and dimensions of the bubble column used in the simulations. (b) and (c) grids for the top and the bottom sections of the reactor.

The Eulerian approach implemented in the commercial code for computational fluid dynamics, FLUENT, has been used for the simulations. The finite volume method is adopted to solve three dimensional governing equations. The solver specifications for the discretization of the domain involve the first-order upwind for momentum and phase coupled SIMPLE [16] for velocity-pressure coupling, respectively. For the volume fraction and concentration of species in the liquid phase, first-order discretization scheme was used. The under-relaxation factors, which are significant parameters affecting the convergence of the numerical scheme, were set to 0.3 for the pressure, 0.5 for the momentum, and 0.5 for the volume fraction. Using mentioned values for the under-relaxation factors a reasonable rate of convergence was achieved. The equations were solved with the unsteady solver with a time step which was $1 \times 10^{-3} \mathrm{~s}$ through the simulations.
The relative error between two successive iterations was specified by using a convergence criterion of $1 \times 10^{-5}$ for each scaled residual component. It is worth noting that refinement of the grids did not produce any significant differences in the results. Air was sparged into the column with different inlet velocities varied from 0 to $0.5 \mathrm{~m} / \mathrm{s}$. According to the experimental results the highest biological oxidation rate of ferrous was obtained using $6.7 \mathrm{~g} / \mathrm{L}$ its initial concentration in the liquid solution, so this initial value was used in the simulation. The bioreactor temperature and the initial bacterial concentration were adjusted equal to the experiments values. The initial ferric concentration was set to zero. Boundary conditions were indicated for solving the governing equations. At the walls, no-slip boundary condition was applied (Dirichlet boundary condition). For inlet flow, constant fluid velocity with given phase concentrations, and for the outlet flow, the pressure were specified as boundary conditions.

\section{RESULTS AND DISCUSSION}

The biological oxidation rate of ferrous iron as a function of concentration at a constant temperature of $32^{\circ} \mathrm{C}$ and inlet air velocity of $0.1 \mathrm{~m} / \mathrm{s}$ is shown in Fig. 3. The experimental results show an inhibition effect on the activity of bacteria when the ferrous iron concentration was higher than $6.7 \mathrm{~g} / \mathrm{L}$. The inhibition effect of ferrous iron on the activity of $A$. ferrooxidans has been reported previously [17]-[19]. Kelly and Jones [17] observed that increases in the ferrous iron concentration up to $5.6 \mathrm{~kg} \mathrm{~m}^{-3}$ increased the rate of biological oxidation, while higher concentrations have the negative effect and inhibited the biooxidation. As can be seen in this figure, the oxidation rate of ferrous iron in the presence of bacteria passed through a maximum which can be explained by a substrate $\left(\mathrm{Fe}^{+2}\right)$ activation and inhibition effect. In addition a comparison between experimental data and the chosen kinetic model confirms the suitability of this model for simulation of ferrous biooxidation in a column bioreactor.

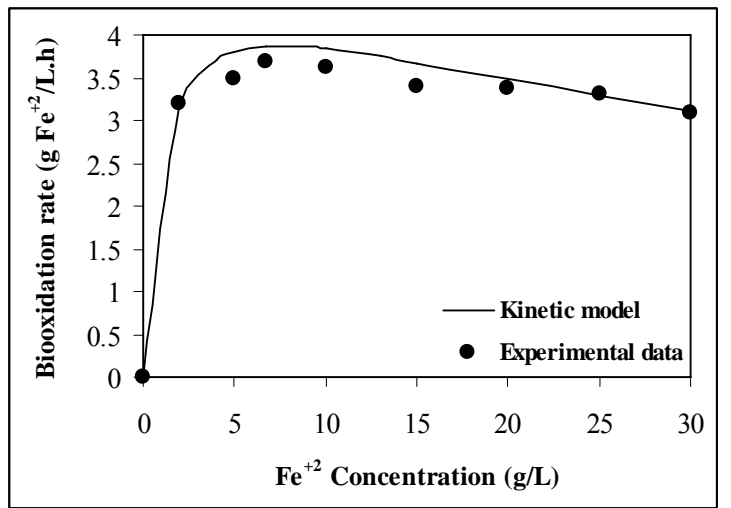

Fig. 3: Comparison of predicted and experimental $\mathrm{Fe}^{+2}$ biooxidation rates at different initial ferrous concentration.

The ferrous biooxidation rate at different inlet air velocities has been presented in Fig. 4. It is clear that inlet air velocity has 
a significant effect on ferrous iron biooxidation. Both experimental and predicted data indicate a maximum rate for air velocity of $0.1 \mathrm{~m} / \mathrm{s}$. In velocities lower than $0.1 \mathrm{~m} / \mathrm{s}$ a decrease was observed in oxygen concentration in the liquid phase because of low gas-liquid interfacial area and therefore, the reaction rate was decreased. At the gas superficial velocities higher than $0.1 \mathrm{~m} / \mathrm{s}$ the biological rate was decreased. The reason is that in very high velocities bacteria will damage and therefore the bacterial activity will be decreased.

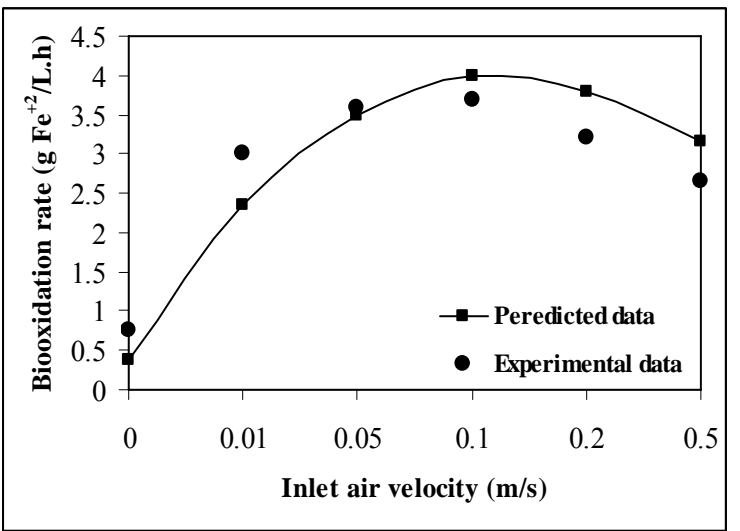

Fig. 4: Comparison of simulated and experimental $\mathrm{Fe}^{+2}$ biooxidation rates at different inlet air velocities.

Figure 5 presents a vector plot of liquid velocity, at the gas superficial velocity of $0.1 \mathrm{~m} / \mathrm{s}$. As can be seen the velocity profile gives a maximum value in the center of the column and a negative value close to the wall, which resembles a liquid flow pattern with liquid up-flow in the center region of the column and down flow near the walls. Air is injected into an initially quiescent liquid. Shortly after the bubbles are released into the column, air rises through the column and creates a typical mushroom like shape (Fig. 6). Due to the gas-liquid momentum coupling, some motion is induced in the liquid phase, and after a while the entire bulk liquid starts to move. After some time the motion inside the bubble becomes unstable. Strong circulation patterns appear with up flow in the center region and down flow in the corners of the column. Due to the liquid down flow, liquid closes to the wall is dragged downwards to the lower region of the column before being dragged again to the column surface by the upward flow. In many of chemical and biochemical reactions which they occur in column reactors gas holdup is an important factor. It affects on interfacial surface area and also activity of microorganisms and therefore the reaction rate. Fig. 6 indicates snapshots of air volume fraction in the bioreactor at $\mathrm{t}=10,30,60,120$, and 180 $\mathrm{s}$. For the ferrous biological oxidation, air volume fraction in the bioreactor is one of the variables that needs to be maximized to have a high reaction rate. Here the inlet air velocity is $0.1 \mathrm{~m} / \mathrm{s}$ and the air volume fraction is evaluated in the plane $(z-y)$ passing through the center of the column.
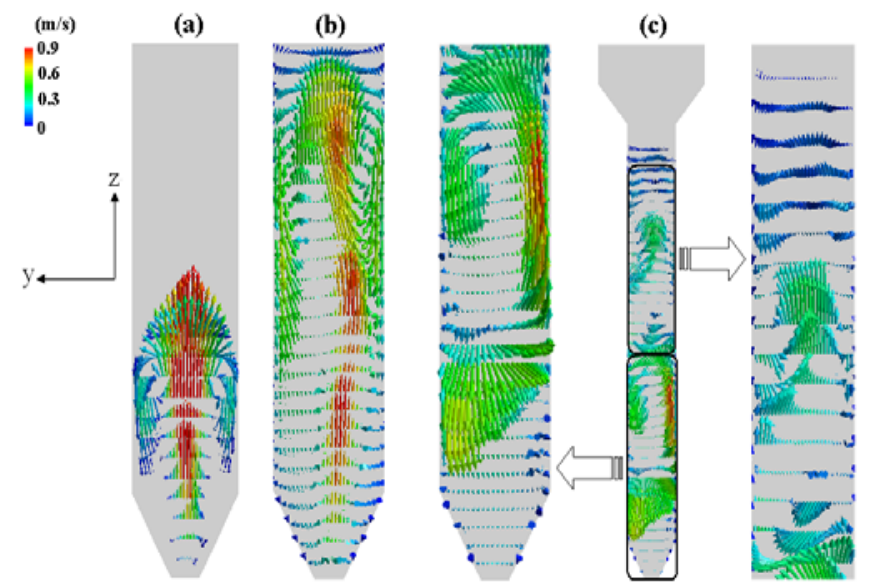

Fig. 5: (a-c) Snapshots of velocity field in the bioreactor at $\mathrm{t}=30,60$ and $180 \mathrm{~s}$. Here the inlet air velocity is $0.1 \mathrm{~m} / \mathrm{s}$. The velocity field was plotted in the plane (z-y) passing through the center of the column.

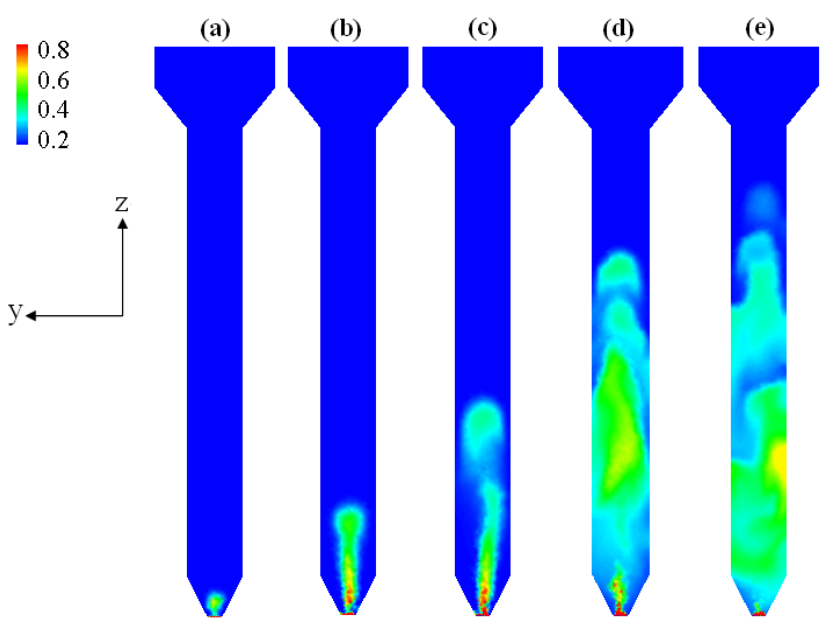

Fig. 6: (a-e) Temporal evaluation of air volume fraction in the bioreactor at $\mathrm{t}=10,30,60,120$, and $180 \mathrm{~s}$. Here the inlet air velocity is $0.1 \mathrm{~m} / \mathrm{s}$. The air volume fraction was evaluated in the plane (z-y) passing through the center of the column.

Fig. 7 shows that at any time the ferrous biological oxidation rate in the column increases from the bottom to top of the reactor. On the other hand, during the air bobbles moving up through the column because of coalescence, their diameters will increase. Therefore, the ferrous biooxidation depends strongly on the gas-liquid interfacial area, and so, gas-liquid mass transfer dominates.

$2 \mathrm{D}$ plots of biooxidation rate in the bioreactor have been shown in Fig. 8. In this picture the results were taken at $\mathrm{t}=120 \mathrm{~s}$. Fig 8 (a) shows the computed ferrous biooxidation rate versus distance from the bottom of the bioreactor. According to this part, the maximum predicted biooxidation rate was obtained in the bioreactor outlet which was about $4 \mathrm{~g} \mathrm{Fe}^{+2} /$ L.h. Fig 8 (b) indicates the rate of biooxidation across several cross sections in the column. As it can be expected at higher sections the reaction rate will increase and on the other hand the maximum value observes in the center of the column because of 
availability of oxygen. Comparison of Figs. 8 and 4 confirms a good agreement between predicted and experimental data.

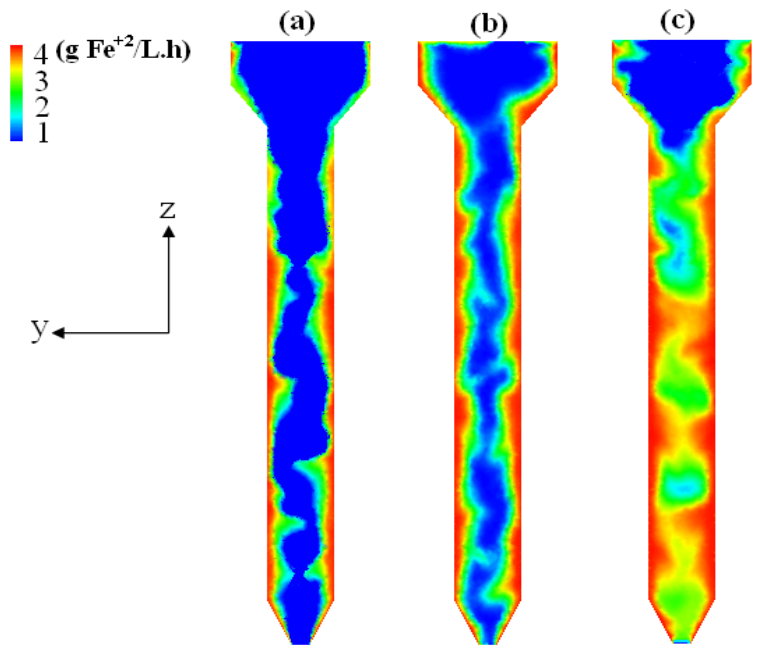

Fig. 7: (a-c) Snapshots of ferrous bioxidation rate in the bioreactor at $\mathrm{t}=60,120$ and $180 \mathrm{~s}$. Here the inlet air velocity is $0.1 \mathrm{~m} / \mathrm{s}$ and initial ferrous concentration set to $6.7 \mathrm{~g} / \mathrm{L}$. The figure was plotted in the plane (z-y) passing through the center of the column.
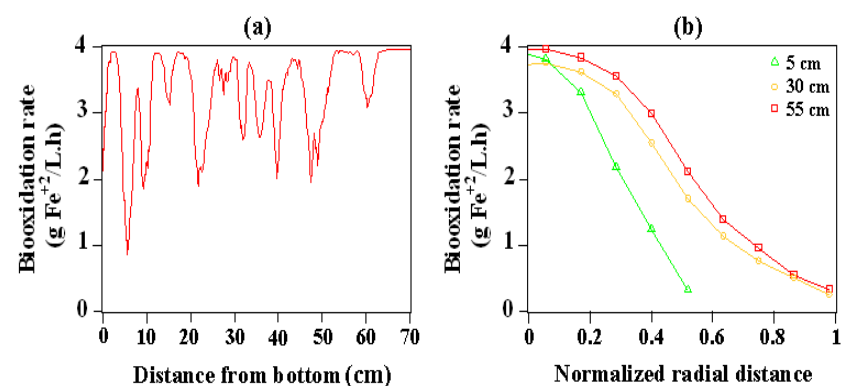

Fig. 8: 2D plots of ferrous biological oxidation rate versus distance in the bioreactor, (a) at z-y plane and (b) at three different $\mathrm{x}-\mathrm{y}$ planes at $\mathrm{t}=120 \mathrm{~s}$.

\section{CONCLUSION}

In this paper bacterial oxidation of ferrous iron in a bubble column reactor was simulated. The results show that CFD allows gaining new insights in the biological phenomena in the gas-liquid reactors. The simulation results indicate that the Eulerian formulation is a successful approach to predict the hydrodynamics of column bioreactor. It provides good engineering descriptions, and can be used reliably for predicting the flow and holdup patterns in bubble columns. The suggested kinetic model by Nemati and Webb was usable for the prediction of ferrous biooxidation rate in the bioreactor. The simulation results indicate good comparison to experimental data for biological ferrous oxidation rate. It was found that the ferrous biological oxidation depends strongly on the gas-liquid interfacial area, and therefore gas-liquid mass transfer dominates. The initial ferrous concentration and the inlet air velocity had a significant effect on the ferrous biooxidation rate. The superficial air velocity of $0.1 \mathrm{~m} / \mathrm{s}$ and initial ferrous concentration of $6.7 \mathrm{~g} / \mathrm{L}$ determined as optimum values. According to the simulation and experiment results maximum ferrous biological oxidation rate was obtained 4 and $3.7 \mathrm{~g} / \mathrm{L} . \mathrm{h}$ at optimum conditions, respectively.

\section{REFERENCES}

[1] M. Blažej, G. M. Cartland Glover, S. C. Generalis, and J. Markoš, "Gas-liquid simulation of an airlift bubble column reactor," Chemical Engineering and Processing, vol. 43, 2004, pp. 137-144.

[2] J. Sanyal, S. Vasquez, S. Roy, and M. P. Dudukovic, "Numerical simulation of gas-/liquid dynamics in cylindrical bubble column reactors," Chemical Engineering Science, vol. 54, 1999, pp. 5071-5083.

[3] A. Sokolichin, and G. Eigenberger, "Applicability of the standard turbulence model to the dynamic simulation of bubble columns: part I. Detailed numerical simulations," Chemical Engineering Science, vol. 54, 1999, pp. 2273-/2284.

[4] R. Krishna, M. I. Urseanu, J. M. van Baten, and J. Ellenberger, "Liquid phase dispersion in bubble columns operating in the churn-turbulent flow regime," Chemical Engineering Journal, vol. 78, 2000, pp. 43-51.

[5] R. Krishna, and J. M. van Baten, "Eulerian simulations of bubble columns operating at elevated pressures in the churn turbulent flow regime," Chemical Engineering Science, vol. 56, 2001, pp. 6249-6258.

[6] J. M. van Baten, and R. Krishna, "Eulerian simulations for determination of the axial dispersion of liquid and gas phases in bubble columns operating in the churn-turbulent regime," Chemical Engineering Science, vol. 56, 2001. pp. 503-512.

[7] G. Cabrera, J. M. Gomez, and D. Cantero, "Influence of heavy metals on growth and ferrous sulphate oxidation by Acidithiobacillus ferrooxidans in pure and mixed cultures," Process Biochemistry, vol. 40, 2005, pp. 2683-2687. [8] H. Magota, and Y. Shiratori, "Treatment of sour natural gas containing hydrogen sulphide,” Japan, 63205124, 1988.

[9] M. Boon, and J. J. Heijnen, "Chemical oxidation kinetics of pyrite in bioleaching processes," Hydrometallurgy, vol. 48, 1998, pp. 27-41.

[10] S. Ebrahimi, R. Kleerebezem, M. C. M. van Loosdrecht, and J. J. Heijnen, "Kinetics of the reactive absorption of hydrogen sulfide into aqueous ferric sulfate solutions," Chemical Engineering Science, vol. 58, 2003, pp. 417-427. [11] M. A. Ronald, Handbook of Microbiological Media. Second Edition, New York: Robert Stern publisher, 1997.

[12] S. M. Mousavi, S. Yaghmaei, and A. Jafari, "Influence of process variables on biooxidation of ferrous sulfate by an indigenous Acidithiobacillus ferrooxidans. Part II: Bioreactor experiments,” Fuel, vol. 86 (7-8), 2007. pp. 993-999.

[13] M. Nemati, and C. Webb, "A kinetic model for biological oxidation of ferrous iron by Thiobacillus ferrooxidans," Biotechnology and Bioengineering. Vol. 53, 1997. pp. 478-486.

[14] P. Chen, M. P. Dudukovic', and J. Sanyal, "Three-dimensional simulation of bubble column flows with bubble coalescence and breakup," AICHE, vol. 51(3), 2005, pp. 696-712.

[15] R. Clift, J. R. Grace, and M. E. Weber, Bubbles, Drops and Particles. San Diego: Academic Press, 1978.

[16] S. A. Vasquez, and V. A. Ivanov, "A phase coupled method for solving multiphase problems on nstructured meshes," In Proceedings of ASME FEDSM'00: ASME 2000 Fluids Engineering Division Summer Meeting, Boston, USA, 2000.

[17] D. P. Kelly, and C. A. Jones, "Factors affecting metabolism and ferrous iron oxidation in suspension and batch culture of Thiobacillus ferrooxidans relevance to ferric leach solution regeneration," pp. 19-43. in Metallurgical Applications of Bacterial Leaching and Related Microbiological Phenomena, L. E. Murr, and J. A. Brierley, Eds. New York: Academic, 1978.

[18] J. L. Barron, and D. R. Luecking, "Growth and maintenance of Thiobacillus ferrooxidans cells," Applied Environment and Microbiology, vol. 56 (9), 1990, pp. 2801-2806.

[19] L. N. Nikolov, and D. G. Karamanev, "Kinetics of the ferrous iron oxidation by resuspended cells of Thiobacillus ferrooxidans," Biotechnology Progress, vol. 8, 1992, pp. 252-255. 